\title{
Status and Reputation Nudging
}

Julia Rose, Michael Kirchler, Stefan Palan

\section{Working Paper 2019-03}

\section{December 2, 2019}

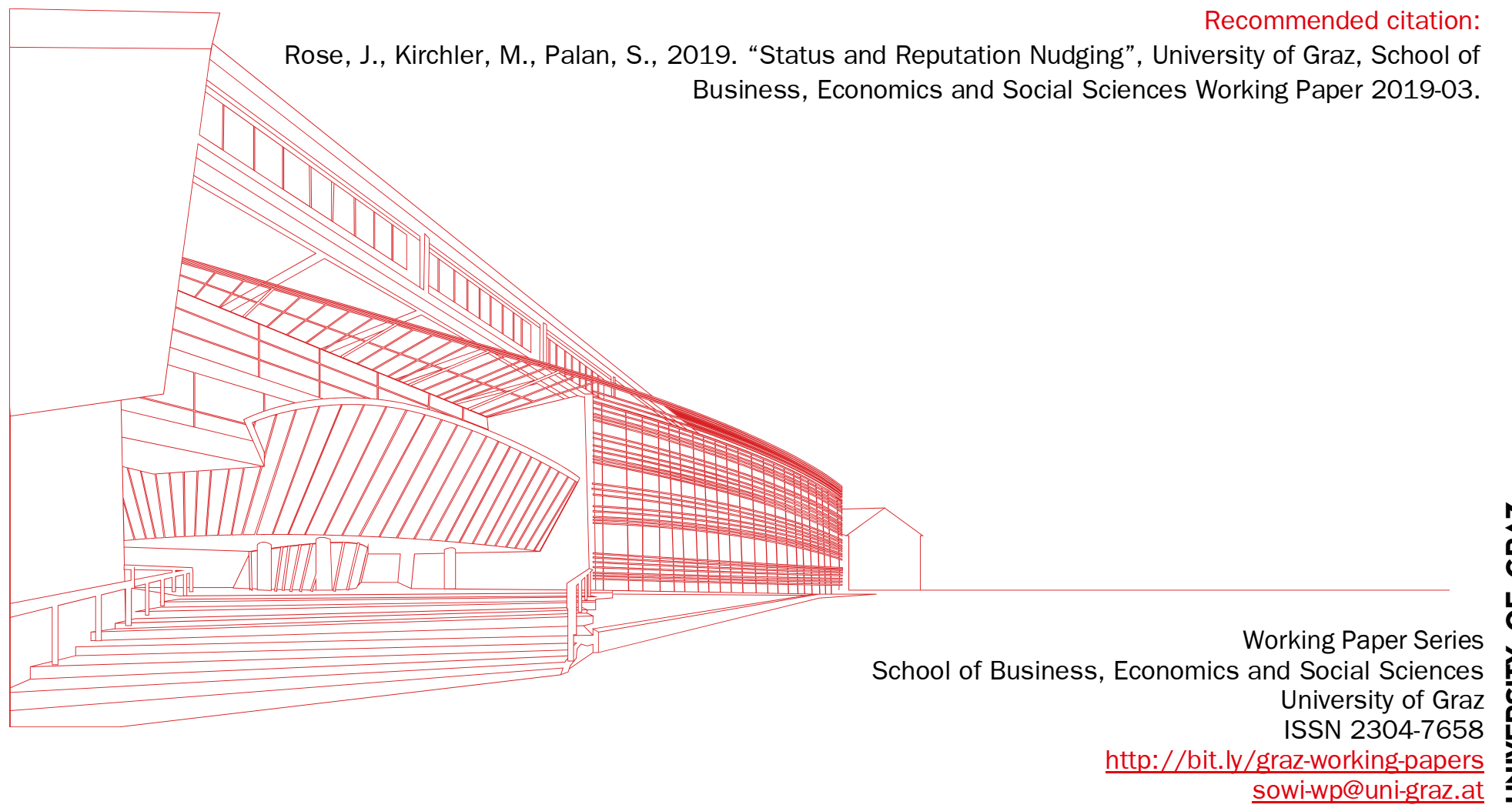




\title{
Status and Reputation Nudging*
}

\author{
Julia Rose $^{\dagger} \quad$ Michael Kirchler ${ }^{\ddagger} \quad$ Stefan Palan ${ }^{\S}$
}

December 2, 2019

\begin{abstract}
Status and reputation concerns are conjectured to be important especially in markets with information asymmetries between buyers and sellers, such as in credence goods markets. To investigate the effects of status and reputation on reciprocal behavior of sales personnel in a financial credence goods market, we run a natural field experiment. We send e-mail requests to insurance brokers asking for an appointment. We find that status nudging and, with a larger effect size, reputation nudging in the e-mails increase brokers' response rates compared to a neutral request. Both effects are robust across all responses, only counting affirmative responses, and in urban and rural areas.
\end{abstract}

JEL: C93, G41, G22, D12

Keywords: Insurance brokers, natural field experiment, credence goods, status, reputation.

${ }^{*}$ We thank Loukas Balafoutas, Stefanie Gäbler, Andrea Schertler, Joep Sonnemans, Thomas Stöckl, and Utz Weitzel for very valuable comments on earlier versions of this paper. We particularly thank Florian Schwaiger for excellent research assistance. Financial support from the Austrian Science Fund FWF (START-grant Y617-G11 and SFB F63) and the Swedish Research Council (grant 2015-01713) is gratefully acknowledged. This study was ethically approved by the IRB of the University of Innsbruck.

Corresponding author: Julia Rose, julia.rose@uibk.ac.at.

${ }^{\dagger}$ University of Innsbruck, Department of Banking \& Finance, Universitätsstrasse 15, 6020 Innsbruck, Austria

${ }^{\ddagger}$ University of Innsbruck, Department of Banking \& Finance, Universitätsstrasse 15, 6020 Innsbruck, Austria

${ }^{\S}$ Corresponding author: University of Graz, Institute of Banking \& Finance, Universitätsstrasse 15, 8010 Graz, Austria 


\section{Introduction}

Evidence from laboratory and field experiments is largely consonant in showing that people reciprocate monetary "gifts" in labor market environments with more effort (see, e.g., Akerlof, 1982; Fehr et al., 1993; Fehr and Gächter, 2000; Charness, 2004; Falk, 2007; Kube et al., 2012; Currie et al., 2013; Cohn et al., 2014). The role of immaterial gifts like compliments, however, has been investigated considerably less comprehensively, and consequently is less clear (Kube et al., 2012). In this study, we operationalize immaterial gifts to sellers as status and reputation nudges, and measure reciprocal behavior in the field in a financial credence goods market. By status and reputation nudges we refer to the practice of ascribing high status or good reputation to a person in direct communication with this person. We report that status nudging and, to an even greater extent, reputation nudging, increase - relative to a neutral request-insurance brokers' response rates following a request for a personal meeting. The effects of both nudges are robust to considering all responses or only positive (i.e., affirmative) responses, and brokers working in urban and rural areas.

Theoretical studies teach us that immaterial gifts like expressions of esteem increase the recipient's utility, which he/she usually reciprocates with additional effort or increased kindness (Brennan and Pettit, 2004; Ellingsen and Johannesson, 2007, 2008, 2011). Evidence from the behavioral labor market literature also shows that immaterial gifts like public recognition programs and awards positively influence work effort (Kosfeld and Neckermann, 2011; Bradler et al., 2014). In a field experiment in experience goods markets, Kirchler and Palan (2018) test the impact of private compliments (thus ruling out utility derived from increased status through public observability of the compliment) on salespersons' reciprocal behavior. The authors show that private compliments to salespeople significantly increase salespeople's reciprocal behavior in everyday interactions with customers (salespeople provide larger portions of ice cream and doner durum in return to compliments). Importantly, the compliments applied in Kirchler and Palan (2018), which are of the type "you have the best ice cream in town", contain both status and reputation components. However, the authors do not address these two components' (separate) impacts.

The two concepts of status and reputation are often used interchangeably despite the fact that they differ along several dimensions (Sorenson, 2014). Status can be seen as an externally assigned measure of social position, and is the consequence of the pattern of social relationships (Patterson et al., 2014; Dimov and De Clercq, 2006). As such, the term "status" is highly intertwined with hierarchical position, an ordering system that is somewhat stable, and a measure of social standing (Podolny, 2010; Patterson et al., 2014). In the case of individuals, status 
depends on the relative position compared to a similar reference group and consequently always stems from social standing (Bitektine, 2011; Sorenson, 2014). This relative social standing gets its value from the fact that not everyone has such standing; given the pyramid shape of the social hierarchy, a social position is higher the fewer people one shares it with (Sorenson, 2014). Additionally, status seeking is observed even when no immediate or delayed monetary returns can be derived from competition (Duesenberry et al., 1949). Reputation, in contrast, is linked to a history of quality, and is defined as a measure of past quality, performance, or actions (Washington and Zajac, 2005; Ertug and Castellucci, 2013; Jensen and Roy, 2008). Reputation is a signal (and not cheap talk) because it usually serves as a proxy for future behavior (Jensen and Roy, 2008). Reputation thus carries information about which products or services to buy (Fombrun, 1996), since it arises from prior actions (Sorenson, 2014).

Sorenson (2014) points out that status is expected to strongly influence choices in situations where customers have difficulty determining the quality of a service, especially because of information asymmetries. This is particularly the case in markets for credence goods, such as markets for health care, repair services, and financial advice. In these markets, consumers, such as patients or private investors, are unable to identify the quality of service that best fits their needs. In contrast, the service providers, such as medical doctors and financial experts, are typically better informed regarding the appropriate quality of service provision (Darby and Karni, 1973; Dulleck and Kerschbamer, 2006). First evidence on the role of high rank (status) in the finance industry (as a credence goods industry closely related to the insurance industry that we study in our experiment) was provided by Kirchler et al. (2018a) and Kirchler et al. (2018b). In labin-the-field experiments with finance professionals, these authors show that professionals strive for high relative rank among their peers in investment decisions, documenting the importance of hierarchical status among financial professionals.

In addition to the importance of their status, the reputation of sellers may also play a crucial role in credence goods markets. According to Kreps et al. (1982), reputational concerns by sellers may lead to more reciprocal behavior, as fraud may be observable in the long run. In contrast, Ely and Välimäki (2003) and Ely et al. (2008) suggest that reputational concerns may lead to less reciprocal behavior. This is the case in markets where an expert's history of service provision - but not of its success - is observable for potential future customers. In such a situation, where only a quantitative but not a qualitative track record is available, providing a specific quality (and thus compromising quantity) may adversely affect a seller's reputation. However, Grosskopf and Sarin (2010), using an experiment, conclude that the positive effects of reputation are generally more widespread than the negative ones.

In this paper, we focus on reciprocal behavior following immaterial gifts in the form of the 
attribution of high status and good reputation to a seller, and we disentangle the two concepts of status and reputation in a financial credence goods market. In particular, we answer the following research question: What is the impact of ascribing status or reputation to a seller (i.e., of status or reputation nudging) on the broker's reciprocal behavior?

To study this question, we conduct a natural field experiment (Harrison and List, 2004) with insurance brokers. We partner with a master's student, who sends e-mail requests to brokers. In these mails, the student asks for an appointment to get answers to some questions for his master's thesis. Importantly, the student who sent these e-mails indeed ran a survey for his thesis and we piggybacked on his design by varying the e-mail request to measure status and reputation effects via brokers' response rates. In particular, we subdivided requests into three different treatments: a neutral wording, a wording ascribing high status to the insurance broker, and a wording ascribing a good reputation to the insurance broker. We then analyze the impact of such status nudging and reputation nudging on the rates of return e-mails. ${ }^{1}$ As a robustness check, we run separate analyses for urban and rural areas. This difference is of particular interest, since the number of insurance brokers in urban and rural areas differs. Sometimes only a handful of brokers serve an entire region in rural areas, working in tight networks.

In the status nudging treatment, we ascribe high status to an insurance broker by writing "After studying several websites [...] I got the impression that you are the expert in the area." In the reputation nudging treatment, we ascribe good reputation to a broker by writing "You were recommended by the majority of my relatives and friends." Hence, in our context, we analyze status as well as reputation as a subjective perception (either deriving from own research on the internet-STATUS, or from advice from family and friends-REPUTATION) rather than as objective characteristics, such as those stemming from public tests and ratings.

Overall, we find that both status and reputation nudging work well. Both nudges significantly increase brokers' response rates compared to the neutral baseline. However, reputation nudging works significantly better than status nudging. These effects are robust to studying either all responses, or only positive (affirmative) responses (i.e., brokers who indicated that they were open to answering the student's questions). Considering urban and rural areas, we observe qualitatively similar patterns overall, but status nudging only significantly increases response rates compared to the neutral baseline in urban areas. These results are supported by logistic regressions as well as linear probability model estimates.

$1 \quad$ We observe all of our variables of interest before the link for participating in the survey was sent out. Since the survey proper thus does not touch upon the results reported in this paper, we refrain from discussing it beyond a few words in section 2. However, further information about the survey is available from the authors upon request. 
Our study is novel in several dimensions. First of all, to the best of our knowledge, we are the first to explore reciprocal behavior following status and reputation nudging in a field environment without monetary incentives. Second, we conduct this study in a credence goods market with professionals - in this case, insurance brokers. Previous field studies investigating reciprocal behavior following immaterial gifts focused on experience goods markets (Kirchler and Palan, 2018). In credence goods markets, however, seller-client relationships are characterized by an important feature that classifies them as credence goods in the sense of Dulleck and Kerschbamer (2006): much of the information and advice a client receives from her broker is not verifiable (by the typical client), because of information asymmetries between clients and brokers (sellers). With our findings - especially the ones on reputation - we add to the studies of Kreps et al. (1982) and Grosskopf and Sarin (2010) in particular, who show that reputational concerns can lead to more reciprocal behavior among expert salespeople. Moreover, our findings on status point in a similar direction as the ones on reputation, and they are in line with the mechanisms suggested by Sorenson (2014). We consider our findings to be important, since they underline the importance of brokers' status and reputation as a potential signal for moderating informational asymmetries between brokers and clients. Hence, it seems that even simple and non-businessrelated requests that address one of the two dimensions trigger more reciprocal behavior among sellers.

\section{The Experiment}

To disentangle the effects of status and reputation nudging, we conduct a novel field experiment with 808 insurance brokers. We study three treatments: (i) Neutral, (ii) Status, and (iii) REPUtATion. We assemble a comprehensive list of independent insurance brokers in Germany by combining the members of the association of German insurance brokers ("Verband Deutscher Versicherungsmakler (VDVM)", since merged to become the "Bundesverband Deutscher Versicherungsmakler e.V. (BDVM)" - all members of this association are independent brokers) with the members of the association of German financial service providers ("Bundesverband Finanzdienstleistung e.V."). In this sense, we thus address the full population, not only a sample, of our target subject pool. Overall, we ended up with 825 e-mail addresses of insurance brokers. Of these, 17 addresses generated non-delivery error messages, leaving us with a final sample of 808 brokers.

In all three treatments, we used e-mail messages with the same baseline text and we approached each insurance broker only once. The master's student we worked with wrote that he was looking for insurance brokers willing to make an appointment to answer a few questions of 
relevance to the student's master's thesis. During the course of the experiment, all e-mails were actually sent by the master's student, from two Gmail addresses in his name. The randomly assigned treatments only differed with respect to the reason the student gave for having chosen the particular broker to contact. In the NEUTRAL baseline treatment, the stated reason for contacting the insurance broker was that the student had come across him/her after studying homepages of insurance brokers and insurance agents. For the STATUs treatment, the student pointed out the specific standing of the insurance broker relative to others in the area (".../ got the impression that you are the expert in the area"). In the reputation treatment, the student emphasized the broker's reputation ("...] you were recommended by the majority of relatives and friends"). We report the full text of the respective e-mails in appendix A1. When brokers replied in the affirmative, the student asked them to fill in a short online survey eliciting preferences concerning altruism, reciprocity, competitiveness, status, reputation and risk.

The main outcome variable of interest is the response rate to our e-mail request. Only personal replies are considered responses; we do not count automatic replies. In our subsequent analysis, we study the content of a responses to categorize it as either positive ${ }^{2}$ or negative ${ }^{3}$. Due to the few cases of non-delivery errors, we ended up successfully sending 275 e-mail requests in the Neutral baseline, 268 requests in the Status treatment, and 265 requests in the RePutation treatment. With respect to the coding, we had three people independently categorizing response emails into positive and negative responses, as well as cases where the response was ambiguous. The third coder, after having finalized his own, independent categorization, studied all three coders' decisions and determined the final assignment of a response to the positive, negative or ambiguous categories (thus resolving inconsistencies in the three coders' independent categorizations). Ambiguous responses, for example, were e-mails with only a question in response to the student's first request for an appointment. ${ }^{4}$ We decided to code these responses as negative, but show (in appendix A3) that our results remain unchanged when instead we code these as positive. It is important to note that we only measure the lower bound of response rates with our experimental design. Our e-mails do not imply the prospect of a future business interaction, which arguably reduces the number of responses across all three treatments compared to a situation where a prospective client were to reach out.

$2 \quad$ An example for a response coded as positive is: "Hello [name of student], that is possible for sure. Please call me to make an appointment. Best regards, [name of insurance broker]."

3 An example for a response coded as negative is: "Dear [name of student], thank you very much for your request. Unfortunately, I have to tell you that I am fully booked until the end of March, since I am also working on a project. I am very sorry. Best regards [name of insurance broker]."

4 An example for that kind of response is: "Dear Mr. [name of student], which questions do you have? Who from your friends and acquaintances recommended me? Please send me your contact details as well as a short CV. Best regards, [name of insurance broker]." 


\section{Results}

Our final sample of 808 messages generated 360 responses across all three treatments (this corresponds to a response rate of 44.6\%; 19 responses, or $5.3 \%$ of the 360 , were ambiguous). When we consider positive responses only, we count 288 replies, which corresponds to a response rate of $35.6 \%$ and to a ratio of $80.0 \%$ of positive responses among all responses. First, we present results regarding overall response rates and regarding positive responses. Second, we test for robustness and divide our analysis into observations collected in rural versus urban areas. Finally, we present regressions to further support our findings.

Result 1 The overall response rate significantly differs between treatments, with REPUTATION $>$ STATUS $>$ NEUTRAL. Both status and reputation nudging significantly and positively affect overall response rates compared to the neutral baseline.

For e-mails with a NEUTRAL content, we count 95 responses, which corresponds to a response rate of $34.5 \%$. The e-mails in treatment STATUS triggered 120 responses (44.8\% response rate), and the e-mails in treatment REPUTATION yielded 145 responses ( $54.7 \%$ response rate). The response rates are depicted in Figure 1. For statistical purposes, we apply Pearson's $\chi^{2}$-tests throughout the whole section unless indicated otherwise. The observed differences are statistically significant in all pairwise comparisons across treatments. STATUs triggers a higher overall response rate than NEUTRAL, with $\chi^{2}(1)=5.940, p=0.015$, and an absolute difference of 10.2 percentage points. The difference between Reputation and Status is significant with $\chi^{2}(1)=5.267, p=0.022$, and a difference of 9.9 percentage points. The difference between the Neutral and Reputation treatments is significant with $\chi^{2}(1)=22.239, p=0.000$, and a percentage point difference of 20.2. An overview with all $p$-values for treatment differences can be found in table A2 in the appendix.

Result 2 The ratio of positive responses to e-mails shows the same pattern as the general response rate. Both status and reputation nudging significantly and positively affect response rates compared to the neutral baseline.

This observed effect of reputation and status nudging on response rates is robust to counting positive responses only, as depicted in Figure 1. Even though the effect size is of course smaller, we nevertheless find significant differences. We receive $27.3 \%$ positive responses in the NEUTRAL baseline. The rate of positive responses in the STATUS treatment is $35.8 \%$, and thus significantly 

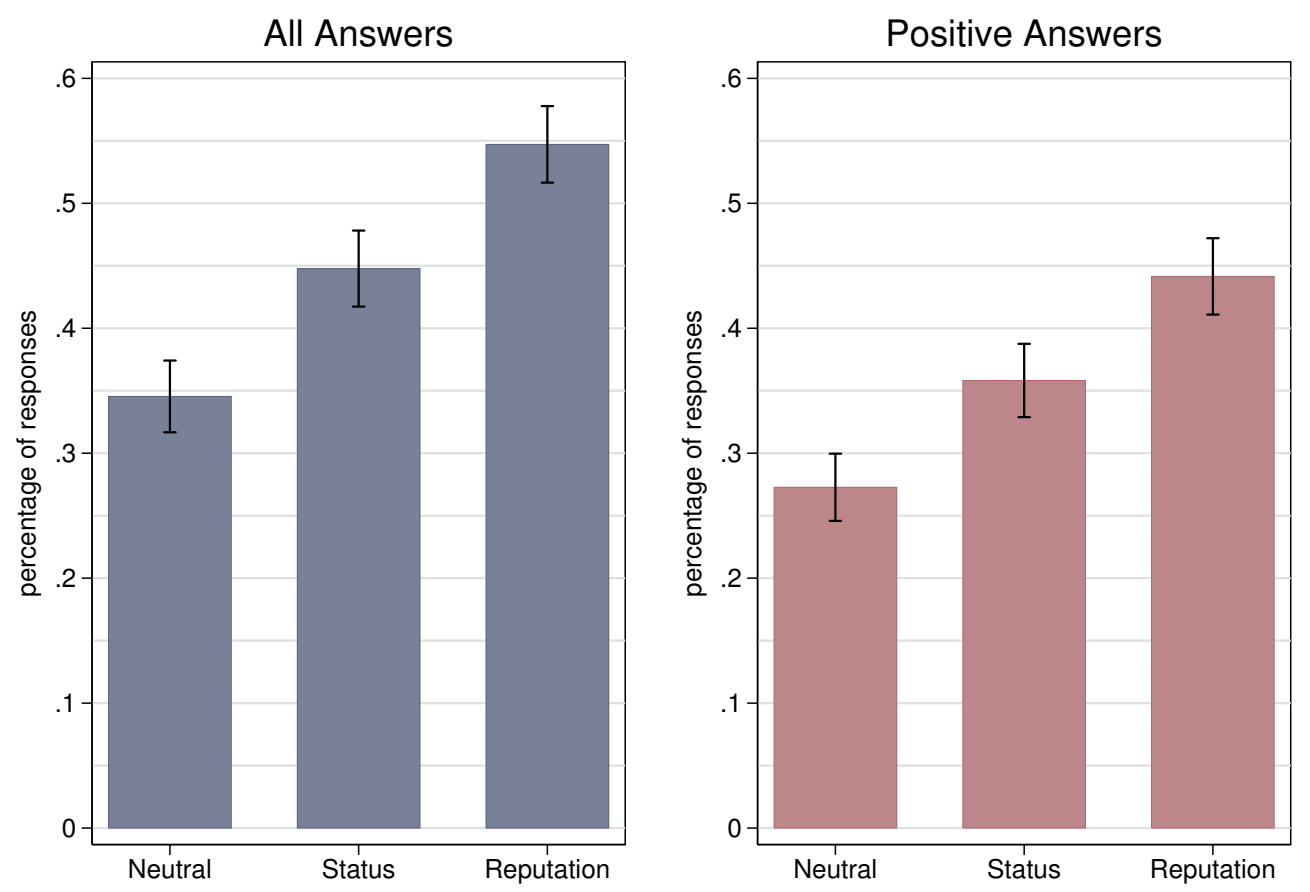

Figure 1: Response rates across treatments for responses overall and for positive responses only: Rates of responses to e-mails requesting an appointment where the student would ask the insurance broker to answer a few questions. Error bars indicate standard errors.

higher $\left(\chi^{2}(1)=4.597, p=0.032\right)$. Compared to Neutral, the Reputation treatment yields a positive difference of 16.9 percentage points, which is highly significant $\left(\chi^{2}(1)=16.778\right.$, $p=0.000)$. Also, we find that ascribing a good reputation to the broker yields a greater proportion of positive responses than ascribing high status $\left(\chi^{2}(1)=3.854, p=0.050\right)$. Taken together, we find that both status and reputation nudging significantly and positively affect both overall and positive response rates. Moreover, we find that reputation nudging works significantly better than status nudging in terms of both overall and positive response rates.

In a next step, we compare the response rates in rural with those in urban areas. ${ }^{5}$ Again we first consider all responses before turning to positive responses only. We are particularly interested in this difference, since the number of insurance brokers in urban areas is high, whereas there are only very few in rural areas - sometimes only a handful for an entire region. In rural areas, insurance brokers often compete for their clients in tightly-linked networks of relatives and acquaintances. Therefore, we hypothesize that reputation nudging in particular will have a

\footnotetext{
$5 \quad$ We obtain data about which municipality belongs to either a rural or an urban area from the German "Bundesinstitut für Bau-, Stadt-, und Raumforschung", which is an administrative unit of the German federal government. We use the website https://www.suche-postleitzahl.org/downloads to associate postcodes with municipalities, relying on data from OpenStreetMap Contributors.
} 
significant and larger effect than in urban areas. Most of our observations stem from urban areas - i.e., we sent 664 requests $(82.2 \%)$ to insurance brokers in urban areas, while we sent only 144 requests $(17.8 \%)$ to rural areas. We provide an overview of the results in Figure 2.

Result 3 Reputation nudging significantly positively affects response rates in both urban and in rural areas. Status nudging significantly positively affects response rates in urban areas only. These results hold both for the set of all responses and for the subset of positive responses.
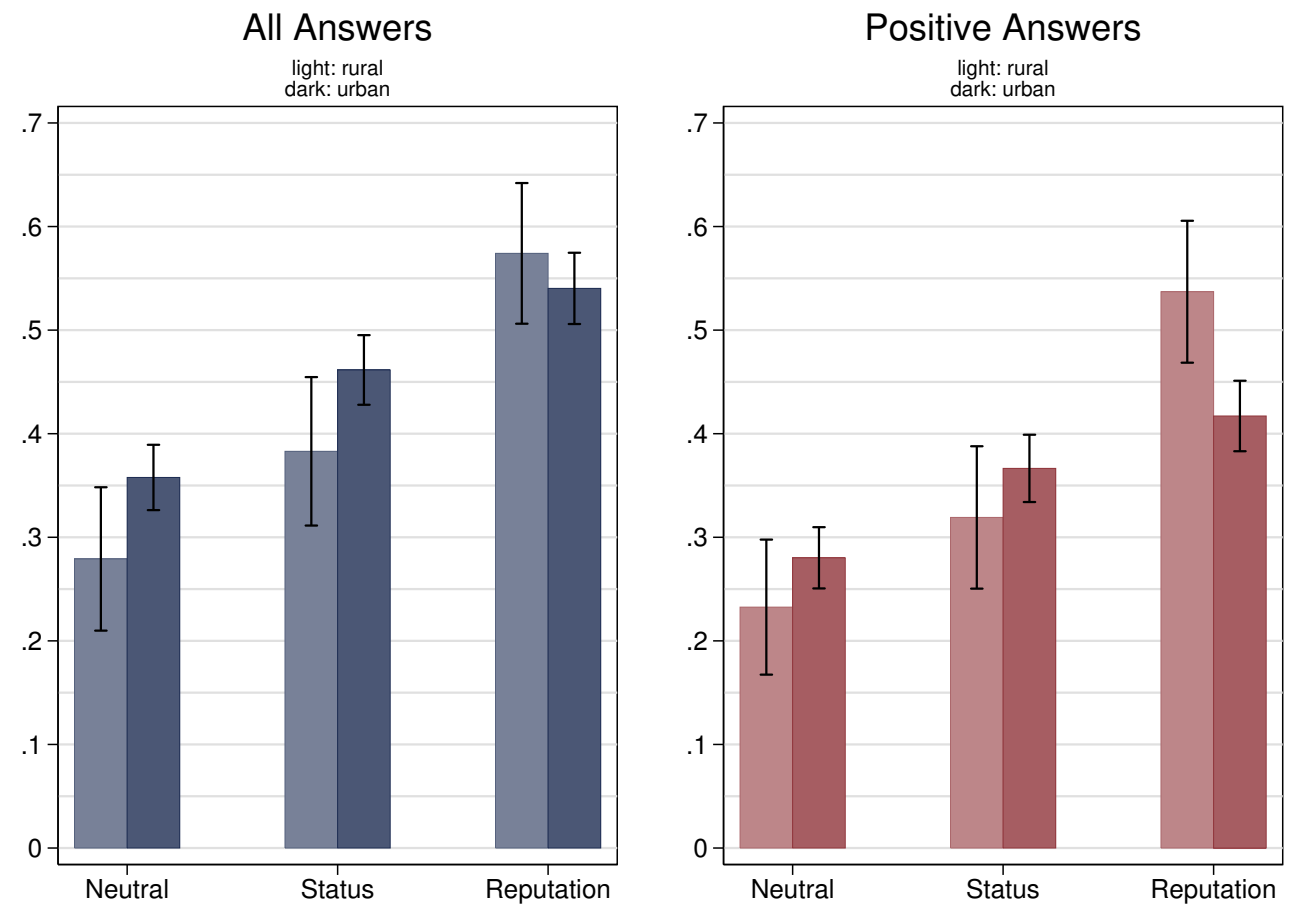

Figure 2: Response rates across treatments for (i) all responses, and for (ii) positive responses only; per geographical area: This graph shows overall and positive rates of response to e-mails requesting an appointment where the student would ask the insurance broker to answer a few questions. The left panel shows all replies, whereas the right panel shows positive replies only. Replies for rural areas are depicted in a slightly lighter shading. Error bars indicate standard errors.

Counting responses overall, we find similar patterns for urban and rural areas as observed in the full sample. Treatment Neutral triggers the lowest response rate, followed by Status and Reputation. However, in comparison to the neutral baseline, status nudging significantly increases overall response rates only in urban areas $\left(\chi^{2}(1)=5.045, p=0.025\right)$, whereas reputation nudging has a significant effect in both areas $\left(\chi^{2}(1)=8.442, p=0.004\right.$ for rural areas; $\chi^{2}(1)=14.908, p=0.000$ for urban areas). When considering positive replies only, we still find a 
significant and positive effect of reputation nudging in both rural and urban areas $\left(\chi^{2}(1)=9.231\right.$, $p=0.002$, and $\chi^{2}(1)=9.159, p=0.002$, respectively). For positive replies and status nudging, we find a significant effect in urban areas $\left(\chi^{2}(1)=3.863, p=0.049\right)$, but not in rural areas $\left(\chi^{2}(1)=0.839, p=0.360\right)$.

In a last step, we run logistic regressions to support our findings. Table 1 presents an overview of the results. The coefficients of the logit regressions (columns (1a), (2a), (1b), and (2b)) are shown in the form of odds ratios. Across all logit specifications, we find that the odds of receiving an answer (or a positive answer) when ascribing high status to an insurance broker are 1.49 to 1.54 times as high as in the NEUTRAL baseline, with $p<0.05$. When ascribing good reputation, we find the odds of receiving an answer (or a positive answer) to be even 2.10 to 2.31 times as high, with $p<0.01$ across all specifications. The effect of the broker being based in a rural area is not significant in either of the models.

The linear probability model specifications (columns (3a), (4a), (5a), (3b), (4b), and (5b)) support the results of our previous analyses as well as the results from the logit regressions for responses overall and for positive responses only. We find that the effect of ascribing good reputation is significant, with $p<0.01$ across all specifications, including when we add a dummy variable for the insurance broker being situated in a rural area, or an interaction term for a rural area and the Reputation treatment. Ascribing status yields a significant effect, with $p<0.05$ across specifications. Across all specifications, the coefficients of the dummy of being situated in a rural area as well as of the interaction terms of this dummy with the STATUs and REPUTATion treatments are not significant.

Finally, our findings warrant some discussion. Generally speaking, the credence goods properties of the insurance brokerage market - i.e., information asymmetries that render a brokers' status and reputation to be important as signals to customers - are potentially a dominant driver of our findings on reciprocal behavior. However, some of the following behavioral concepts might also have served as candidate contributors.

First, especially addressing brokers' reputation (and, to a lesser degree, brokers' status) in the e-mail request may have the effect of reducing social distance, i.e., "the emotional proximity induced by the situation" (Charness and Gneezy, 2008, p. 30). Such a reduction has been found to induce increased kindness (Hoffman et al., 1996; Charness and Gneezy, 2008). In our experiment, this means that the social distance to insurance brokers may have been reduced in the reputation treatment because the e-mail sender references the people who recommended the broker. These recommenders ostensibly know both sides of the interaction, the sender and the broker. 
Table 1: Logit and Linear Probability Model Estimation Results: This table outlines Logit and Linear Probability Model estimates for replies overall and for positive replies only across several specifications. Robust standard errors are given in parentheses. The last line displays the $p$-values of post-estimation Wald-tests for the coefficients of Status and RePUtATiOn being equal. Stars indicate significance levels levels, ${ }^{* * *} \mathrm{p}<0.01,{ }^{* *} \mathrm{p}<0.05$.

\begin{tabular}{|c|c|c|c|c|c|c|c|c|c|c|}
\hline & \multicolumn{4}{|c|}{ All Replies } & \multirow[b]{2}{*}{ Model } & \multicolumn{4}{|c|}{ Positive Replies } & \multirow[b]{2}{*}{ Model } \\
\hline & \multirow{2}{*}{$\begin{array}{l}\text { Logit } \\
\text { (1a) }\end{array}$} & Model & Linear & Probability & & \multicolumn{2}{|c|}{ Logit Model } & \multicolumn{2}{|c|}{ Linear Probability } & \\
\hline & & $(2 \mathrm{a})$ & $(3 a)$ & $(4 a)$ & $(5 a)$ & $(1 \mathrm{~b})$ & $(2 \mathrm{~b})$ & $(3 \mathrm{~b})$ & $(4 b)$ & $(5 b)$ \\
\hline Constant & $0.5278^{* * *}$ & $0.5406^{* * *}$ & $0.3455^{* * *}$ & $0.3513^{* * *}$ & $0.3578^{* * *}$ & $0.375^{* * *}$ & $0.3715^{* * *}$ & $0.2727^{* * *}$ & $0.2706^{* * *}$ & $0.2802^{* * *}$ \\
\hline & $(0.0669)$ & $(0.0703)$ & $(0.0287)$ & $(0.0297)$ & $(0.0316)$ & $(0.0508)$ & $(0.0516)$ & $(0.0269)$ & $(0.0279)$ & $(0.0296)$ \\
\hline Status & $1.5363^{* *}$ & $1.5413^{* *}$ & $0.1023^{* *}$ & $0.1030^{* *}$ & $0.1038^{* *}$ & $1.4884^{* *}$ & $1.4867^{* *}$ & $0.0855^{* *}$ & $0.0852^{* *}$ & $0.0863^{* *}$ \\
\hline & $(0.2712)$ & $(0.2723)$ & $(0.0418)$ & $(0.0418)$ & $(0.0462)$ & $(0.2767)$ & $(0.2765)$ & $(0.0398)$ & $(0.0399)$ & $(0.0440)$ \\
\hline Reputation & $2.2895^{* * *}$ & $2.3082^{* * *}$ & $0.2017^{* * *}$ & $0.2035^{* * *}$ & $0.1825^{* * *}$ & $2.1081^{* * *}$ & $2.1023^{* * *}$ & $0.1688^{* * *}$ & $0.1681^{* * *}$ & $0.1369 * * *$ \\
\hline & $(0.4051)$ & $(0.4093)$ & $(0.0420)$ & $(0.0420)$ & $(0.0467)$ & $(0.3866)$ & $(0.3860)$ & $(0.0407)$ & $(0.0407)$ & $(0.0451)$ \\
\hline Rural & & 0.8544 & & -0.0377 & -0.0787 & & 1.0612 & & 0.0135 & -0.0476 \\
\hline & & $(0.1613)$ & & $(0.0445)$ & $(0.0756)$ & & $(0.2043)$ & & $(0.0435)$ & $(0.0711)$ \\
\hline Rural x Status & & & & & 0.0001 & & & & & 0.0002 \\
\hline & & & & & $(0.1091)$ & & & & & $(0.1038)$ \\
\hline Rural x Reputation & & & & & 0.1125 & & & & & 0.1676 \\
\hline & & & & & $(0.1070)$ & & & & & $(0.1042)$ \\
\hline $\mathrm{N}$ & 808 & 808 & 808 & 808 & 808 & 808 & 808 & 808 & 808 & 808 \\
\hline$R^{2}$ & 0.0202 & 0.0208 & 0.0275 & 0.0284 & 0.0301 & 0.0160 & 0.0161 & 0.0207 & 0.0209 & 0.0250 \\
\hline Log-likelihood & -544.0626 & -543.7137 & & & & -517.8416 & -517.7942 & & & \\
\hline$p-v_{a l u e^{a}}$ & 0.022 & 0.021 & 0.022 & 0.020 & & 0.050 & 0.051 & 0.050 & 0.051 & \\
\hline
\end{tabular}

$\bar{a} \quad$ This line displays the $p$-values of post-estimation Wald-tests for the coefficients of STATUS and RePUTATION being equal. 
Second, guilt aversion (Charness and Dufwenberg, 2006; Battigalli and Dufwenberg, 2007; Ellingsen et al., 2010) could be another channel partly driving our results. The concept of guilt aversion is connected to the beliefs of the insurance broker. Translated to our experiment, it would postulate that brokers feel guilty (and so incur a utility loss), whenever their behavior does not live up to their beliefs about the expectations of the e-mail inquirer. However, Ellingsen et al. (2010) point out that measuring guilt aversion is difficult even in a lab environment. If guilt aversion plays a role, its effect should be present in all treatments in a similar way.

To sum up, because of our field setting, we cannot measure the roles of either candidate contributor for our major findings. However, we believe that sellers' preferences for reciprocal behavior, together with the credence goods properties of the market - the latter of which drives insurance brokers' desire for high status and reputation as a signal to customers - serve as the major drivers of our findings.

\section{Conclusion}

In this paper, we conduct a field experiment with 808 insurance brokers in a credence goods environment. Our aim is to analyze the effects of non-monetary imputations of status and reputation (i.e., status and reputation nudging) on insurance brokers' reciprocal behavior, measured by the response rates following e-mail requests.

Our findings show that both status nudging and reputation nudging significantly increase the response rates to e-mails. We find that this effect holds for replies overall and for positive replies only. We also find that the observed patterns remain qualitatively unchanged when dividing the sample into urban and rural areas.

To summarize, we contribute to the literature twofold. First, we explore the effects of an appeal to status and reputation on the response rates in an environment where monetary incentives or compensation do not play a role. We ensure this by asking expert sellers for a meeting to discuss questions in the absence of an intent to purchase. Second, the study is conducted as a natural field experiment with insurance brokers in their natural environment, which gives us the opportunity to analyze status- and reputation-related behavior in a financial credence goods market "in the wild". Hence, the findings potentially underline the importance of experts' status and reputation signalling in markets with information asymmetries, and demonstrate simple nudges that trigger more reciprocal behavior among experts. 


\section{References}

Akerlof, George A. 1982. Labor contracts as partial gift exchange. Quarterly Journal of Economics 97 543-569.

Battigalli, Pierpaolo, Martin Dufwenberg. 2007. Guilt in games. American Economic Review 97(2) 170-176.

Bitektine, Alex. 2011. Toward a theory of social judgments of organizations: The case of legitimacy, reputation, and status. Academy of Management Review 36(1) 151-179.

Bradler, Christine, Robert Dur, Susanne Neckermann, Arjan Non. 2014. Employee recognition and performance: A field experiment. IZA DP No. 8311 1-29.

Brennan, Geoffrey, Philip Pettit. 2004. The economy of esteem. Oxford University Press.

Charness, Gary. 2004. Attribution and reciprocity in an experimental labor market. Journal of Labor Economics 22(3) 665-688.

Charness, Gary, Martin Dufwenberg. 2006. Promises and partnerships. Econometrica 74(6) 1579-1601.

Charness, Gary, Uri Gneezy. 2008. What's in a name? anonymity and social distance in dictator and ultimatum games. Journal of Economic 68 29-35.

Cohn, Alain, Ernst Fehr, Lorenz Götte. 2014. Fair wages and effort provision: combining evidence from a choice experiment and a field experiment. Management Science forthcoming.

Currie, Janet, Wanchuan Lin, Juanjuan Meng. 2013. Social networks and externalities from gift exchange: Evidence from a field experiment. Journal of Public Economics 107 19-30.

Darby, Michael, Edi Karni. 1973. Free competition and the optimal amount of fraud. Journal of Law and Economics 16 67-88.

Dimov, Dimo, Dirk De Clercq. 2006. Venture capital investment strategy and portfolio failure rate: A longitudinal study. Entrepreneurship Theory and Practice 30(2) 207-223.

Duesenberry, James Stemble, et al. 1949. Income, saving, and the theory of consumer behavior. Harvard University Press.

Dulleck, Uwe, Rudolf Kerschbamer. 2006. On doctors, mechanics, and computer specialists: The economics of credence goods. Journal of Economic Literature 44(1) 5-42.

Ellingsen, Tore, Magnus Johannesson. 2007. Paying respect. Journal of Economic Perspectives 21 135-149. 
Ellingsen, Tore, Magnus Johannesson. 2008. Pride and prejudice: the human side of incentive theory. American Economic Review 98(3) 990-1008.

Ellingsen, Tore, Magnus Johannesson. 2011. Conspicuous generosity. Journal of Public Economics 95 1131-1143.

Ellingsen, Tore, Magnus Johannesson, Sigve Tjotta, Gaute Torsvik. 2010. Testing guilt aversion. Games and Economic Behavior 68 95-107.

Ely, Jeffrey C., Drew Fudenberg, David K. Levine. 2008. When is reputation bad? Games and Economic Behavior 63 498-526.

Ely, Jeffrey C., Juuso Välimäki. 2003. Bad reputation. Quarterly Journal of Economics 118(3) 785-814.

Ertug, Gokhan, Fabrizio Castellucci. 2013. Getting what you need: How reputation and status affect team performance, hiring, and salaries in the NBA. Academy of Management Journal 56(2) 407-431.

Falk, Armin. 2007. Gift exchange in the field. Econometrica 75(5) 1501-1511.

Fehr, Ernst, Simon Gächter. 2000. Fairness and retaliation: the economics of reciprocity. Journal of Economics Perspectives 14 159-181.

Fehr, Ernst, George Kirchsteiger, Arno Riedl. 1993. Does fairness prevent market clearing? an experimental investigation. Quarterly Journal of Economics 108(2) 437-459.

Fombrun, Charles J. 1996. Reputation: Realizing value from the corporate image.

Grosskopf, Brit, Rajiv Sarin. 2010. Is reputation good or bad? an experiment. American Economic Review 5 2187-2204.

Harrison, Glenn W., John A. List. 2004. Field experiments. Journal of Economic Literature 42 $1009-1055$.

Hoffman, Elizabeth, Kevin McCabe, Vernon L. Smith. 1996. Social distance and other-regarding behavior in dictator games. American Economic Re 86(3) 653-660.

Jensen, Michael, Aradhana Roy. 2008. Staging exchange partner choices: When do status and reputation matter? Academy of Management Journal 51(3) 495-516.

Kirchler, Michael, Florian Lindner, Utz Weitzel. 2018a. Delegated decision making and social competition in the finance industry. Working Paper .

Kirchler, Michael, Florian Lindner, Utz Weitzel. 2018b. Rankings and risk-taking in the finance industry. The Journal of Finance 73(5) 2271-2302. 
Kirchler, Michael, Stefan Palan. 2018. Immaterial and monetary gifts in economic transactions. evidence from the field. Experimental Economics 21(1) 205-230.

Kosfeld, Michael, Susanne Neckermann. 2011. Getting more work for nothing? symbolic awards and worker performance. American Economic Journal: Microeconomics 3(3) 86-99.

Kreps, David M., Paul Milgrom, John Roberts, Robert Wilson. 1982. Rational cooperation in the finitely repeated prisoners dilemma. Journal of Economic Theory 27 245-252.

Kube, Sebastian, Michel André Maréchal, Clemens Puppe. 2012. The currency of reciprocity: gift exchange in the workplace. American Economic Review 102(4) 1644-1662.

Patterson, Karen, David Cavazos, Marvin Washington. 2014. It does matter how you get to the top: Differentiating status from reputation. Administrative Sciences 4(2) 73-86.

Podolny, Joel M. 2010. Status signals: A sociological study of market competition. Princeton University Press.

Sorenson, Olav. 2014. Status and reputation: Synonyms or separate concepts? Strategic Organization 12(1) 62-69.

Washington, Marvin, Edward J Zajac. 2005. Status evolution and competition: Theory and evidence. Academy of Management Journal 48(2) 282-296. 


\section{Online Appendix}

\section{A1 E-Mail Contents}

The following three blocks reproduce English translations, followed by the German original, of the text of the e-mails sent to insurance brokers in our three treatments. To highlight the parts of the text that changed by treatment, we print this text in italics.

\section{Neutral}

Subject: Request for information

Dear Mr./Ms. [LastName],

I am working on my master's thesis focusing on the insurance industry and have a few questions for you. Would it be possible to make an appointment with you? I came across your name after studying several websites of insurance brokers and insurance agents.

Yours sincerely,

[FirstName LastName]

Betreff: Bitte um Information

Sehr geehrter Herr/geehrte Frau [Nachname],

Ich arbeite gerade an meiner Masterarbeit zum Thema Versicherungswirtschaft und hätte ein paar Fragen an Sie. Wäre es möglich mit Ihnen einen Termin zu vereinbaren? Ich bin beim Studium diverser Webseiten von Versicherungsvermittlern und Versicherungsmaklern auf Sie gestoßen.

Mit freundlichen Grüßen,

[Vorname Nachname]

\section{Status}

Subject: Request for information

Dear Mr./Ms. [LastName], 
I am working on my master's thesis focusing on the insurance industry and have a few questions for you. Would it be possible to make an appointment with you? After studying several websites of insurance brokers and insurance agents I got the impression that you are the expert in the area.

Yours sincerely,

[FirstName LastName]

Betreff: Bitte um Information

Sehr geehrter Herr/geehrte Frau [Nachname],

Ich arbeite gerade an meiner Masterarbeit zum Thema Versicherungswirtschaft und hätte ein paar Fragen an Sie. Wäre es möglich mit Ihnen einen Termin zu vereinbaren? Nach dem Studium diverser Webseiten von Versicherungsvermittlern und Versicherungsmaklern habe ich den Eindruck gewonnen, dass Sie der Experte in der Gegend sind.

Mit freundlichen Grüßen, [Vorname Nachname]

\section{Reputation}

Subject: Request for information

Dear Mr./Ms. [LastName],

I am working on my master's thesis focusing on the insurance industry and have a few questions for you. Would it be possible to make an appointment with you? You were recommended by the majority of my relatives and friends.

Yours sincerely,

[FirstName LastName]

Betreff: Bitte um Information

Sehr geehrter Herr/geehrte Frau [Nachname],

Ich arbeite gerade an meiner Masterarbeit zum Thema Versicherungswirtschaft und hätte ein paar Fragen an Sie. Wäre es möglich mit Ihnen einen Termin zu vereinbaren? Sie wurden mir von meinem Verwandten- und Bekanntenkreis mehrheitlich empfohlen. 
Mit freundlichen Grüßen,

[Vorname Nachname]

\section{A2 Additional Results}

Out of the 825 e-mail requests sent, 17 could not be delivered. The remaining 808 e-mails were split across treatments as depicted in table A1. We received a total of 360 e-mails in response to our 808 requests, which corresponds to a response rate of $44.55 \%$.

Table A1: Response rates across treatments: This table shows response rates to e-mails requesting an appointment where the student would ask the insurance broker to answer a few questions.

\begin{tabular}{lcccc}
\hline & Baseline & Status & Reputation & Sum \\
\hline E-mails sent & 275 & 268 & 265 & 808 \\
Total replies & $95(34.6 \%)$ & $120(44.8 \%)$ & $145(54.7 \%)$ & 360 \\
Positive replies & $75(27.3 \%)$ & $96(35.8 \%)$ & $117(44.2 \%)$ & 288 \\
Negative replies & $19(6.9 \%)$ & $19(7.1 \%)$ & $15(5.7 \%)$ & 53 \\
Ambiguous replies & $1(0.4 \%)$ & $5(1.9 \%)$ & $13(4.9 \%)$ & 19 \\
\hline
\end{tabular}

Table A2: Test results for treatment differences for responses overall and for positive replies only: This table shows $p$-values from pairwise Pearson's $\chi^{2}$ tests of differences in response rates between treatments.

\begin{tabular}{lcccc}
\hline & \multicolumn{2}{c}{ All Responses } & \multicolumn{2}{c}{ Positive Responses } \\
\cline { 2 - 5 } & Reputation & Status & Reputation & Status \\
\hline NeUtRal & 0.000 & 0.015 & 0.000 & 0.032 \\
Status & 0.022 & - & 0.050 & - \\
\hline
\end{tabular}

Table A3 reports the absolute numbers of responses separately for urban and for rural areas. Table A4 lists $p$-values from Pearson's $\chi^{2}$ tests. 
Table A3: Absolute number of responses across treatments overall and for positive responses only - urban and rural areas: This table shows the absolute numbers of responses to e-mails requesting an appointment where the student would ask the insurance broker to answer a few questions.

\begin{tabular}{lcccccc}
\hline & \multicolumn{3}{c}{ Urban } & \multicolumn{3}{c}{ Rural } \\
\cline { 2 - 7 } & Neutral & Status & Reputation & Neutral & Status & Reputation \\
\hline All responses & $83(35.8 \%)$ & $102(46.2 \%)$ & $114(54.0 \%)$ & $12(27.9 \%)$ & $18(38.3 \%)$ & $31(57.4 \%)$ \\
Positive responses & $65(28.0 \%)$ & $81(36.7 \%)$ & $88(41.7 \%)$ & $10(23.3 \%)$ & $15(31.9 \%)$ & $29(53.7 \%)$ \\
Negative responses & $17(7.3 \%)$ & $17(7.7 \%)$ & $13(6.2 \%)$ & $2(4.7 \%)$ & $2(4.3 \%)$ & $2(3.7 \%)$ \\
Ambiguous responses & $1(0.4 \%)$ & $4(1.8 \%)$ & $13(6.2 \%)$ & $0(0.0 \%)$ & $1(2.1 \%)$ & $0(0.0 \%)$ \\
\hline $\mathrm{N}$ & 232 & 221 & 211 & 43 & 47 & 54 \\
\hline
\end{tabular}

Table A4: Test results for treatment differences for responses overall and for positive responses only - urban and rural areas: This table shows $p$-values from Pearson's $\chi^{2}$ tests of differences in response rates between treatments, separately for urban and rural areas.

\begin{tabular}{lcccccccc}
\hline & \multicolumn{4}{c}{ Urban } & \multicolumn{4}{c}{ Rural } \\
\cline { 2 - 9 } & \multicolumn{2}{c}{ All responses } & \multicolumn{2}{c}{ Positive responses } & \multicolumn{2}{c}{ All responses } & \multicolumn{2}{c}{ Positive responses } \\
& Reputation & Status & RePUtation & Status & Reputation & Status & Reputation & Status \\
\hline NeUtral & 0.000 & 0.025 & 0.002 & 0.049 & 0.004 & 0.296 & 0.002 & 0.360 \\
Status & 0.102 & - & 0.282 & - & 0.055 & - & 0.028 & - \\
\hline
\end{tabular}




\section{A3 Results with Ambiguous Responses Counted as Positive}

In the following, we present the results for ambiguous responses to our initial request. Tables A1 and A3 already gave an overview of the absolute numbers and proportions of ambiguous responses we received. A response of that kind is, for example: "Dear Mr. [name of student], which questions do you have? Who from your friends and acquaintances recommended me? Please send me your contact details as well as a short CV. Best regards, Iname of insurance broker]". In response to our 808 e-mails we received 307 (38.0\%) positive responses when counting ambiguous responses as positive and not as negative, as we did in our main analysis. Figure A1 displays the response rates for positive responses. All differences are statistically significant. The response rate in the STATUs treatment is significantly higher than in the NeUTRAL baseline $\left(\chi^{2}(1)=6.240, p=0.012\right)$, and the response rate in the REPUTATION treatment is significantly higher than in the neutral baseline $\left(\chi^{2}(1)=26.243, p=0.000\right)$. Additionally, the response rate in the REPUTATION treatment is significantly higher than in the STATUS treatment $\left(\chi^{2}(1)=7.015, p=0.008\right)$. Table A5 reports the $p$-values of the full set of pairwise comparisons including the distinction between urban and rural locations.

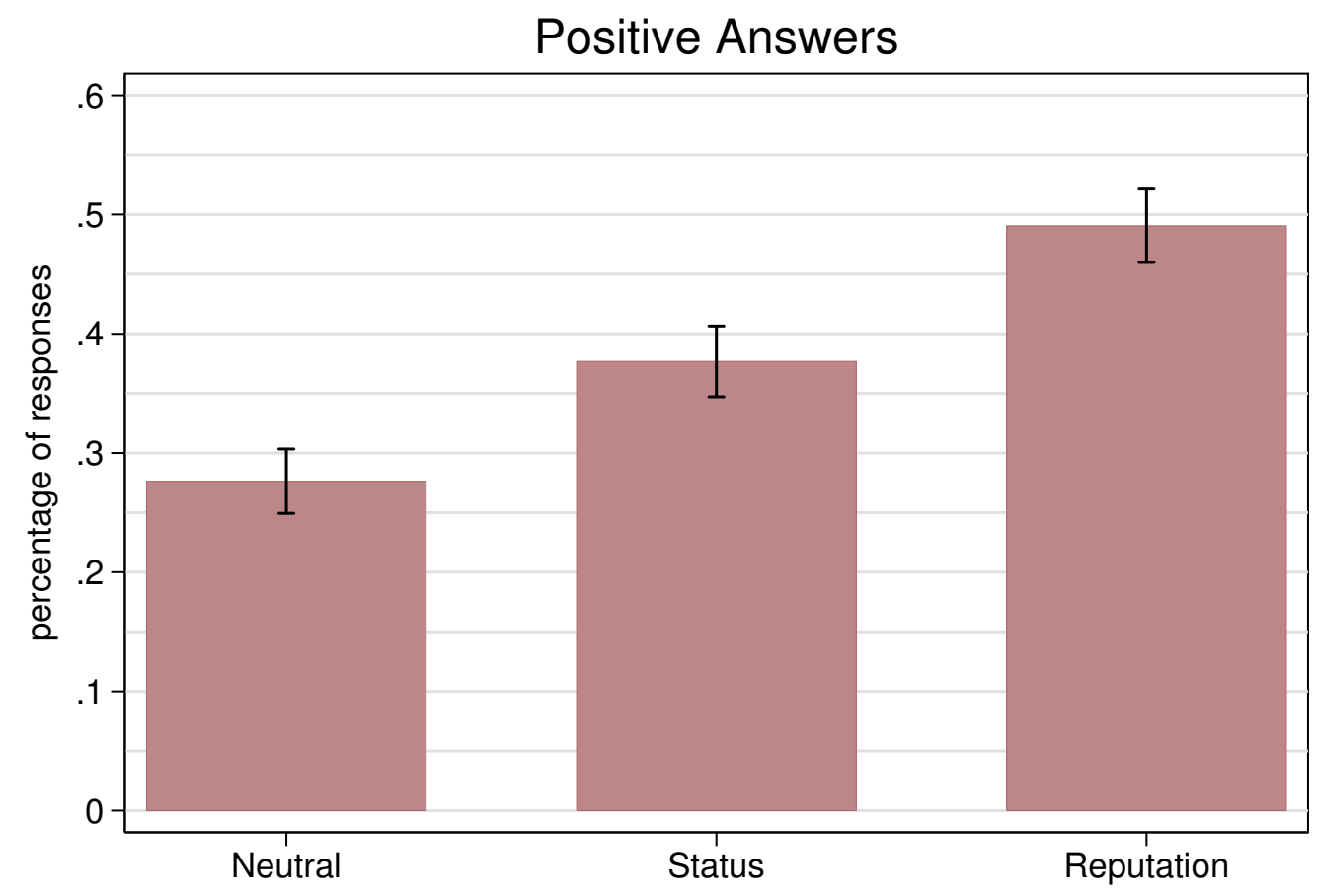

Figure A1: Response rates across treatments for positive responses: Rates of responses to e-mails requesting an appointment where the student would ask the insurance broker to answer a few questions. Error bars indicate standard errors. 


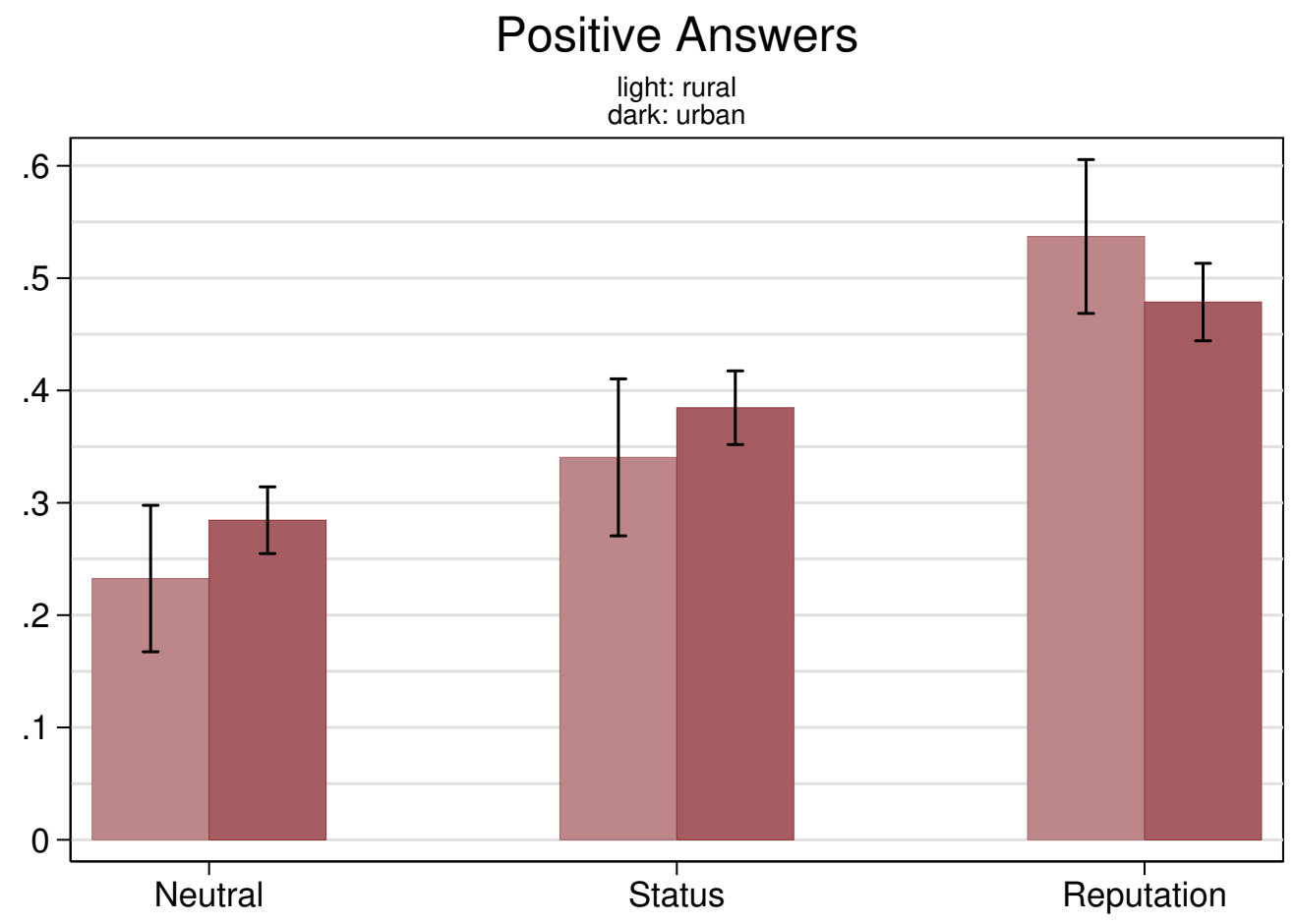

Figure A2: Response rates across treatments for positive responses only per geographical area: This graph shows the positive response rates to e-mails requesting an appointment where the student would ask the insurance broker to answer a few questions. Replies for rural areas are depicted in a slightly lighter shading. Error bars indicate standard errors. 
Table A5: Test results for treatment differences for responses overall and for positive responses only - urban and rural areas: This table shows $p$-values from Pearson's $\chi^{2}$ tests of differences in response rates between treatments, separately for urban and rural areas.

\begin{tabular}{|c|c|c|c|c|c|c|c|c|}
\hline & \multicolumn{4}{|c|}{ Urban } & \multicolumn{4}{|c|}{ Rural } \\
\hline & \multicolumn{2}{|c|}{ All responses } & \multicolumn{2}{|c|}{ Positive responses } & \multicolumn{2}{|c|}{ All responses } & \multicolumn{2}{|c|}{ Positive responses } \\
\hline & REPUtATion & Status & REPUTATION & Status & REPUTATION & Status & RePutATion & Status \\
\hline Neutral & 0.000 & 0.025 & 0.000 & 0.024 & 0.004 & 0.296 & 0.002 & 0.259 \\
\hline Status & 0.102 & - & 0.048 & - & 0.055 & - & 0.047 & - \\
\hline
\end{tabular}

